\title{
Effect of treatment with retinyl palmitate, progesterone, oestradiol and tamoxifen on secretion of a protein similar to retinol-binding protein during uterine gland development in neonatal pigs
}

\author{
J. L. Vallet ${ }^{1}$, R. K. Christenson ${ }^{1}$, F. F. Bartol ${ }^{2}$ and A. A. Wiley ${ }^{2}$ \\ ${ }^{1}$ USDA, ARS, Roman L. Hruska US Meat Animal Research Center, Clay Center, NE, USA; and \\ ${ }^{2}$ Department of Animal and Dairy Science, Auburn University, AL, USA
}

\begin{abstract}
Previous work has demonstrated that uterine secretion of a protein with $M_{\mathrm{r}} 20000$ and pI 5.5 increases during neonatal endometrial gland development. Uterine tissue was collected from a 60-day-old gilt and cultured in $0.1 \times$ leucine minimum essential medium (MEM) plus $50 \mu \mathrm{Ci}\left[{ }^{3} \mathrm{H}\right]$ leucine to determine whether this protein is related to retinolbinding protein (RBP). Conditioned medium was immunoprecipitated using anti-human RBP antiserum. A radioactive protein with $M_{\mathrm{r}} 20000$ and pI 5.5 was specifically immunoprecipitated from the conditioned medium. Uteri from neonatal gilts were collected at birth (day 0) and on days 3,6,9 and 12, cultured, and secreted proteins were immunoprecipitated as described above to determine whether secretion of immunoreactive RBP increased coincident with initiation of endometrial gland development. Immunoprecipitation demonstrated that the secretion of immunoreactive RBP increased by day 3. Finally, gilts were treated each day with corn oil, retinyl palmitate (10 000 iu day ${ }^{-1}$ ), progesterone $\left(20 \mathrm{mg} \mathrm{day}^{-1}\right)$, oestradiol ( $100 \mu \mathrm{g} \mathrm{day}^{-1}$ ) or tamoxifen ( $1 \mathrm{mg} \mathrm{day}{ }^{-1}$ or $0.1 \mathrm{mg} \mathrm{day}^{-1}$ ) for 14 days beginning at birth to determine the effects of these treatments on endometrial gland development and uterine secretion of immunoreactive RBP. On day 14, gilts were killed and uteri collected. Uterine tissue samples were prepared for histology (to evaluate uterine development using morphometry) and for culture in $0.1 \times$ methionine MEM plus $25 \mu \mathrm{Ci}$ $\left[{ }^{35}\right.$ S]methionine (to evaluate uterine protein synthesis). Secretion of immunoreactive RBP was evaluated by immunoprecipitation. Retinyl palmitate increased $(P<0.05)$ glandular epithelial area without altering other uterine components or secretion of uterine immunoreactive RBP. Progesterone decreased $(P<0.05)$ secretion of uterine immunoreactive RBP but did not affect uterine histological measurements. Treatment with oestradiol and I mg tamoxifen day ${ }^{-1}$ stimulated $(P<0.01)$ secretion of uterine immunoreactive RBP and increased all the uterine components measured $(P<0.01)$. These results are consistent with a role for $R B P$ and retinol in the development of the uterus during the neonatal period.
\end{abstract}

\section{Introduction}

The size of litters in pigs is influenced by ovulation rate, fertilization rate, embryonic mortality and uterine capacity (Christenson et al., 1987). The extent and efficiency of uterine development during prepuberty in gilts can be expected to influence uterine capacity during pregnancy.

At birth, the uterine wall consists of a perimetrial epithelial layer, developing myometrial layers and an endometrial layer made up of stromal cells and luminal epithelial cells. No endometrial glands are present. However, within one week, endometrial glands begin to differentiate and continue to develop for the next 2-3 months (Hadek and Getty, 1959; Bal and Getty, 1970).

Received 3 May 1994.
Recent studies in pigs indicate that uterine secretion of several proteins change during the period of endometrial gland development (Christenson et al., 1992; Spencer et al., 1992). One of these proteins $\left(M_{\mathrm{T}} 20000, \mathrm{pI} 5.5\right)$, which is similar to porcine retinol-binding protein (RBP; Clawitter et al., 1990; Harney et al., 1990; Trout et al., 1991), increases during the period of uterine gland development. Retinol is known to influence differentiation in various tissues, including several types of epithelium (DeLuca, 1991) through the regulation of genes such as the genes encoding keratin (Stellmach et al., 1991), tissue plasminogen activator (Rickles et al., 1989), laminin (Vasios et al., 1989), matrix Gla protein (Cancela and Price, 1992) and transglutaminase (Yuspa et al., 1982). Agerelated changes in neonatal uterine secretion of RBP suggest that retinol may be involved in the process of uterine gland development. 
If an association between the secretion of RBP and endometrial morphogenesis can be demonstrated, factors affecting RBP secretion may help elucidate the role of RBP in endometrial morphogenesis. The adult porcine endometrium secretes RBP in response to progesterone (Adams et al., 1981) and possibly oestrogen (Trout et al., 1992). Chronic progestin exposure from birth to day 13 inhibited endometrial gland development in neonatal sheep (Bartol et al., 1988). In addition, retinol is required for efficient hepatic secretion of RBP (Goodman, 1979; Ronne et al., 1983). Therefore, progesterone and retinol could be used to investigate relationships between uterine wall development and RBP secretion in neonatal gilts. Oestradiol has been shown to stimulate uterine development in neonatal gilts (Spencer et al, 1992). Tamoxifen increases uterine mass in pigs (Lin and Buttle, 1991) but inhibits gland development in rats (Branham et al., 1985a). Therefore, oestradiol and tamoxifen could also be used in testing the association between uterine development and RBP secretion in neonatal gilts.

The objectives of this study were to: (1) determine whether the $M_{\mathrm{r}} 20000$, pl 5.5 protein crossreacts with antiserum to human RBP; (2) characterize the secretion of this protein by the uterus during the first 2 weeks of life in gilts and (3) determine whether treatment with retinyl palmitate, progesterone, oestradiol or tamoxifen influences uterine development and protein secretion (including putative RBP).

\section{Materials and Methods}

\section{Experiment 1}

The uterus of a 60-day-old crossbred gilt ( $\frac{1}{4}$ Yorkshire, $\frac{1}{4}$ Large White, $\frac{1}{4}$ Chester White and $\frac{1}{4}$ Landrace) was collected at slaughter and $500 \mathrm{mg}$ of tissue was cultured in $15 \mathrm{ml} 0.1 \times$ leucine minimum essential medium (MEM; Sigma Chemical Co., St Louis, MO) together with $50 \mu \mathrm{Ci}\left[{ }^{3} \mathrm{H}\right]$ leucine (Amersham Corp., Arlington Heights, IL). The tissue was cultured for $24 \mathrm{~h}$ at $37^{\circ} \mathrm{C}$ in an atmosphere of $50 \% \mathrm{~N}_{2}: 45 \% \mathrm{O}_{2}$ : $5 \% \mathrm{CO}_{2}$ (Vallet and Christenson, 1993) and conditioned medium was collected by centrifugation ( $10 \mathrm{~min}, 2500 \mathrm{~g}, 4^{\circ} \mathrm{C}$ ).

Duplicate samples $(3 \mathrm{ml})$ of conditioned medium were incubated overnight sequentially with $50 \mu \mathrm{I}$ anti-human RBP antiserum (Dako, Carpinteria, CA) or normal rabbit serum, followed by $100 \mu \mathrm{l} 10 \%(\mathrm{w} / \mathrm{v})$ protein $\mathrm{A}$ linked to Sepharose CL-4B previously equilibrated in $50 \mathrm{mmol}$ Tris $\mathrm{l}^{-1}, 0.3 \mathrm{~mol}$

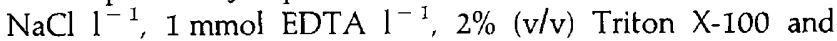
$0.02 \%(w / v)$ sodium azide (Buffer A). Samples were centrifuged (10 min, $2500 \mathrm{~g}, 4^{\circ} \mathrm{C}$ ), the supernatant discarded and the pellet washed five times with Buffer A. One hundred microlitres of $5 \mathrm{mmol} \mathrm{K} \mathrm{CO}_{3} \mathrm{l}^{-1}, 2 \%$ Triton $\mathrm{X}-100(\mathrm{v} / \mathrm{v}), 9.16 \mathrm{~mol}_{\text {urea }} \mathrm{l}^{-1}$, $0.5 \%(\mathrm{w} / \mathrm{v})$ dithiothreitol were then added and samples subjected to two-dimensional PAGE. Gels were then prepared for fluorography (28-day exposure; Roberts et al., 1984).

\section{Experiment 2}

Twenty crossbred neonatal gilts were randomly assigned at birth (day 0 ) to be killed on day $0,3,6,9$ or 12 of age $(n=4$ per day). Gilts were stunned with a captive bolt, exsanguinated and the uterus collected aseptically. Uteri were weighed and each uterus with a mass of less than $400 \mathrm{mg}$ was cut into small pieces using a scalpel and cultured. Each uterus weighing more than $400 \mathrm{mg}$ was evenly distributed between two culture plates. Tissues were cultured as previously described. Conditioned medium was dialysed (three changes of $4 \mathrm{I}$, dialysed overnight: $M_{r}$ cutoff 3500; Spectrapor, Fisher

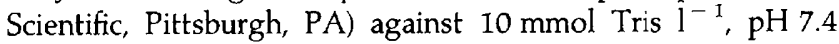
and nondialysable radioactivity was determined. Aliquots containing $10^{6}$ d.p.m. non-dialysable radioactivity were immunoprecipitated with $25 \mu \mathrm{l}$ antiserum and subjected to SDS-PAGE and fluorography (4-month exposure). Immunoprecipitation of two to three times this volume of medium did not saturate the antibody (data not shown). Densitometry of fluorographs was used to quantitate relative amounts of immunoreactive RBP resulting from immunoprecipitation.

\section{Experiment 3}

Thirty-three crossbred neonatal gilts were randomly assigned at birth to receive either 10000 iu retinyl palmitate day $^{-1}$ (provided by Stuart Products Inc., Bedford, TX); $20 \mathrm{mg}$ progesterone day ${ }^{-1} ; 100 \mu \mathrm{g}_{\text {oestradiol day }}{ }^{-1} ; 1$ or $0.1 \mathrm{mg}$ tamoxifen day ${ }^{-1}$ or $0.5 \mathrm{ml}$ vehicle day ${ }^{-1}(90 \%$ corn oil, $10 \%$ ethanol) from birth and continuing for 14 days. The dose of retinyl palmitate was 17 times greater than the requirement recommended by the National Research Council (1988) because of uncertainties about availability to uterine tissues. Blood samples $(3-5 \mathrm{ml})$ were collected on days 5,10 and 14 before daily injections. On day 14, gilts were weighed, killed and uteri collected. The broad ligament was trimmed and the uterus was weighed. For histological assessment, a $1 \mathrm{~cm}$ section of the uterine horn collected at the uterine bifurcation was fixed in $4 \%(\mathrm{w} / \mathrm{v})$ paraformaldehyde PBS. Additional uterine tissue (200 mg) was cultured for $24 \mathrm{~h}$ in $0.1 \times$ methionine MEM plus $25 \mu \mathrm{Ci}\left[{ }^{35} \mathrm{~S}\right]$ methionine $\left(1190 \mathrm{Ci} \mathrm{mmol}{ }^{-1}\right.$, NEN Dupont, Wilmington, DE).

After incubation, $\left[{ }^{35} \mathrm{~S}\right]$ methionine radiolabelled culture medium was dialysed as previously described and nondialysable radioactivity was determined. Aliquots $(1 \mathrm{ml})$, were then immunoprecipitated ( $25 \mu \mathrm{l}$ antiserum or normal rabbit serum) and the immunoprecipitates were subjected to SDS-PAGE and fluorography (28-day exposure). The antiserum used in this experiment was raised against porcine RBP purified from allantoic fluid (Vallet, 1993). An additional I ml aliquot was lyophilized and subjected to two-dimensional PAGE and fluorography (28-day exposure) to examine secreted proteins other than immunoreactive RBP.

\section{Assays for retinol-binding protein, retinol and progesterone}

Plasma samples from control and retinyl palmitate-treated gilts were assayed for RBP (Vallet, 1994). Intra- and interassay coefficients of variation for the assay were 11.0 and $10.4 \%$, respectively. The limit of detection of the assay was $0.46 \mathrm{ng}$.

Retinol in plasma was determined using a modification of the method of Selvaraj and Sushella (1970). Briefly, $0.5 \mathrm{ml}$ of $1 \mathrm{~mol}$ $\mathrm{KOH} 1^{-1}$ in $95 \%$ ethanol was added to $0.5 \mathrm{ml}$ of serum and incubated at $60^{\circ} \mathrm{C}$ in capped tubes for $2 \mathrm{~h}$. Samples were extracted with $3 \mathrm{ml}$ xylene, frozen on dry ice and the xylene 
pl

6.5

29.0

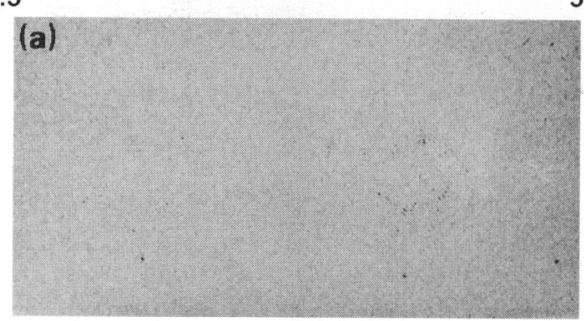

12.5

29.0

0
$\dot{x}$
$\dot{x}$

12.5

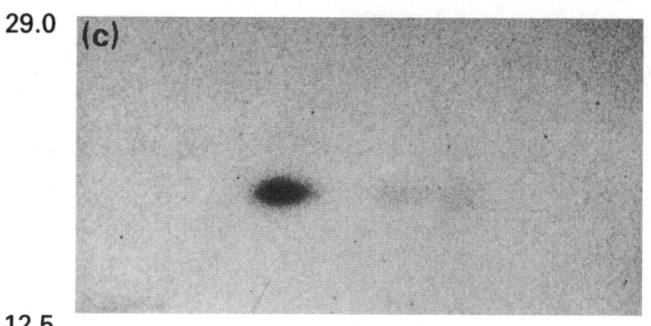

12.5

Fig. 1. Fluorographs (28-day exposure) of two-dimensional PAGE gels illustrating results of immunoprecipitation of $\left[{ }^{3} \mathrm{H}\right]$ leucine-labelled uterine secreted proteins with either (a) normal rabbit serum (whole serum), (b) normal rabbit serum (rabbit gamma globulin) or (c) anti-human retinol-binding protein (RBP) antiserum (isolated IgG). Note spots in (c) indicating positive immunoprecipitation of immunoreactive RBP $\left(M_{\mathrm{r}}\right.$ approximately 20000 ; one major ( $\mathrm{pI}$ approximately 5.6) and two minor (pl approximately 5.3 and 5.2) isoforms were observed).

was collected. Retinol fluorescence in the xylene extracts was measured on a Perkin Elmer fluorometer at $330 \mathrm{~nm}$ excitation, $470 \mathrm{~nm}$ emission. Retinol concentrations were corrected for recovery (approximately $70 \%$ ).

Plasma progesterone concentrations were determined by radioimmunoassay. The antibody used was prepared against progesterone-11-BSA (Cambridge Medical, Billerica, MA). The assay was validated by demonstrating quantitative recovery of exogenous progesterone added to plasma and parallelism of increasing volumes of plasma to the standard curve. The intraand interassay coefficients of variation were 9.1 and $14.2 \%$, respectively. The limit of detection of the assay was $0.15 \mathrm{pg}$.

\section{Preparation and evaluation of histological sections}

Fixed tissue was dehydrated, embedded in paraffin wax, sectioned $(5 \mu \mathrm{m})$, mounted on slides and stained with haematoxylin and eosin. Two sections (at least $\mathrm{I} \mathrm{mm}$ apart) from

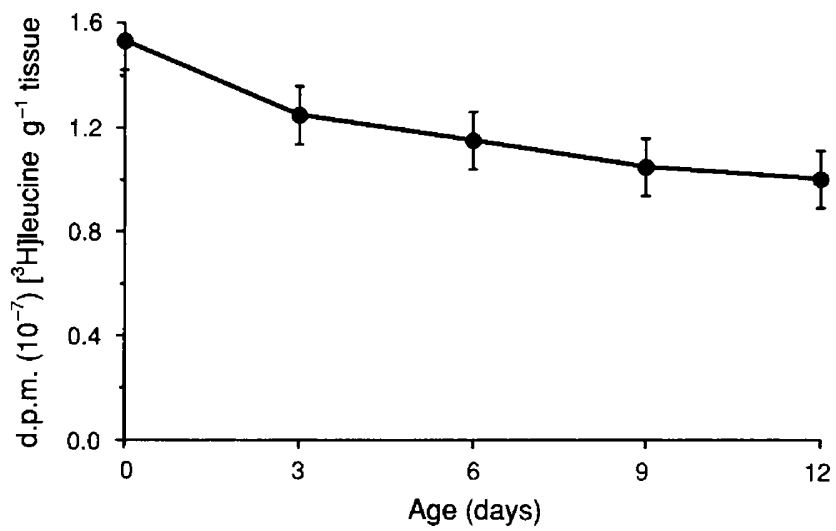

Fig. 2. Mean nondialysable radioactivity (d.p.m. $10^{-7} \times\left[{ }^{3} \mathrm{H}\right]$ leucine $\mathrm{g}^{-1}$ tissue) in medium from cultures of uteri collected from $0-, 3-, 6-$, 9- and 12-day-old gilts. A negative linear effect of day of age was detected $(P<0.01)$.

each uterus from each gilt were evaluated for total uterine cross-sectional, longitudinal myometrial, circular myometrial, endometrial, endometrial gland epithelial and luminal epithelial area to assess gland development. Morphometric analysis was performed using a Microcomp Integrated Image Analysis System (Southern Micro Instruments, Aflanta, GA), after calibration using a slide micrometer. The external border of the uterus, the border between the longitudinal and circular myometrium, the border between the myometrium and endometrium, the basal border of the luminal epithelium and the luminal border were encircled and the areas within these borders were calculated. Longitudinal myometrial area was defined as the total uterine cross-sectional area minus the area within the longitudinal-circular myometrial border. Similar calculations were made to obtain circular myometrial, endometrial and luminal epithelial area. Endometrial glands were defined as groups of epithelial cells that surrounded a closed lumen separated from the uterine lumen by interposed cells (Branham et al., 1985b). To determine glandular epithelial area, the area within the lumen of each gland was determined, summed and subtracted from the sum of the areas of each gland.

\section{Statistical analyses}

Data for nondialysable radioactivity in culture medium from Expt 2 were subjected to analysis of variance, using a model that included the effect of day, and regression analysis, using day as a continuous independent variable. Data resulting from densitometry of the $20000 \mathrm{M}_{\mathrm{r}}$ immunoreactive RBP band (area under the curve) were log transformed and subjected to analysis of variance using a model that included the effects of gel (four samples were run on each gel for a total of five gels) and day. This analysis is reported because gels were loaded on the basis of similar nondialysable radioactivity, a procedure used by Spencer ef al. (1992). However, because the amount of nondialysable radioactivity decreased linearly with age of the gilt, sample loading based on nondialysable radioactivity may not fully compensate for differences in tissue masses. Therefore, in a separate analysis, these data were expressed as relative 


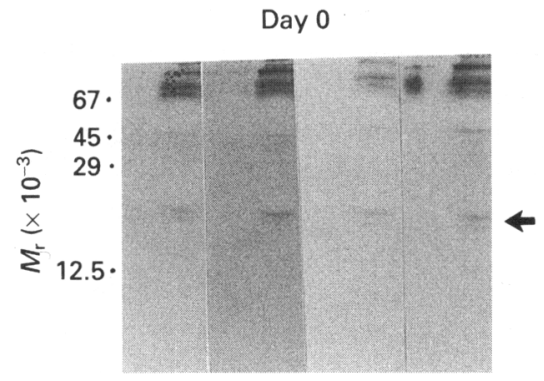

Day 9

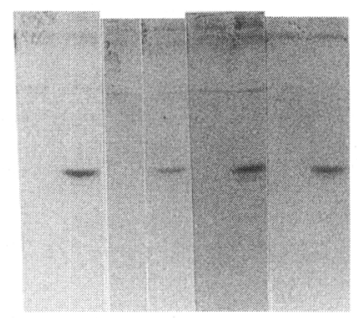

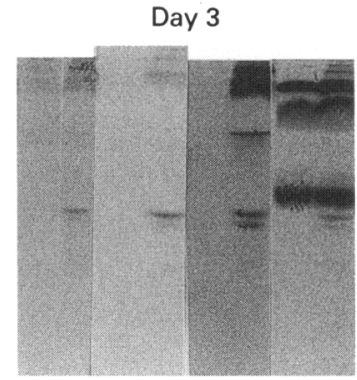

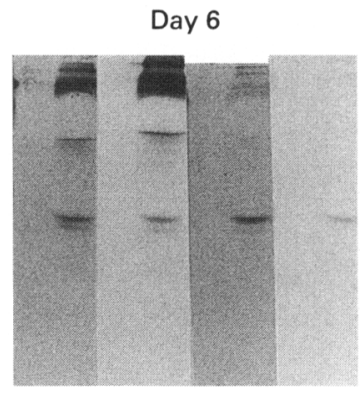

Day 12

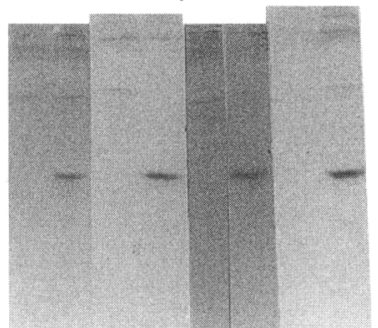

Fig. 3. Fluorographs (4-month exposure) resulting from immunoprecipitation of $\left[{ }^{3} \mathrm{H}\right]$ leucine-labelled proteins secreted into culture medium by uterine tissue from $0-, 3-, 6-, 9-$ or 12-day-old gilts $(n=4$ at each age). Fluorographs are arranged in pairs depicting results obtained from individual gilts. For each pair at each age, proteins immunoprecipitated using rabbit gamma globulin (negative control) are in the first lane and proteins immunoprecipitated with anti-retinol-binding protein (RBP) are in the second lane. The arrow indicates the position of immunoreactive RBP bands. Note the presence of two bands of immunoreactive RBP (approximately 20000 and $19000 M_{\mathrm{r}}$ ) on days 0 to 6 and the absence of the lower molecular weight band by day 12. The other bands represent proteins that are precipitated by anti-human RBP and normal rabbit serum (not shown), but that are not precipitated by rabbit gamma globulin.

units per milligramme tissue to correct for tissue masses in each culture, and then subjected to analysis of variance using a model that included the effects of gel and day. In both analyses, the following set of orthogonal contrasts was performed: day 9 versus day 12; day 6 versus days 9 and 12 combined; day 3 versus days 6,9 and 12 combined; and day 0 versus days 3,6 , 9 and 12 combined. Densitometry data for the $19000 M_{\mathrm{r}}$ RBP band were analysed as described above, except that the following set of orthogonal contrasts was used: day 3 versus day 6; day 1 versus days 3 and 6 combined; day 9 versus day 12; and days 0,3 and 6 combined versus days 9 and 12 combined.

For Expt 3, plasma RBP, retinol and progesterone were analysed by analysis of variance, using a model that included effects of treatment, gilt within treatment, day of age and day of age by treatment interaction. Simple correlations were calculated between RBP secreted in culture, incorporation of $\left[{ }^{35} S\right]$ methionine into nondialysable radioactivity, uterine area, longitudinal myometrial area, circular myometrial area, endometrial area, glandular epithelial area and luminal epithelial area. Areas of uterine components were analysed with and without log transformation using a model that included effects of treatment and gilt within treatment. The untransformed error variance and gilt within treatment variance were used to calculate repeatability estimates of these measurements. Log-transformed data and the following contrasts were used to examine treatment effects in detail: control versus progesterone-treated groups (effect of progesterone); control versus retinyl palmitate-treated group (effect of retinyl palmi- tate); control versus $0.1 \mathrm{mg}$ tamoxifen day ${ }^{-1}$ treated group (effect of low tamoxifen dose); oestradiol-treated group versus $1 \mathrm{mg}$ tamoxifen day ${ }^{-1}$ treated group (comparison of the two potentially oestrogenic treatments) and control, progesterone, retinyl palmitate and $0.1 \mathrm{mg}$ tamoxifen day ${ }^{-1}$ treated groups combined versus oestradiol and I mg tamoxifen day ${ }^{-1}$ treated groups combined (comparison of potentially non-oestrogenic treatments with oestrogenic treatments). The first three contrasts are not orthogonal but each is orthogonal with the last two contrasts; the last two contrasts are orthogonal with each other. Body mass on day 14, uterine mass, RBP secreted in culture and incorporation of $\left[{ }^{35} \mathrm{~S}\right]$ methionine into nondialysable macromolecules were analysed by analysis of variance using a model that included the effect of treatment. The contrasts described above were used to define treatment differences. RBP secreted in culture was log transformed before analysis.

\section{Results}

\section{Experiment 1}

The anti-human RBP antiserum specifically immunoprecipitated one major $(\mathrm{pl}=5.6)$ and two minor $(\mathrm{pI}=5.3,5.2)$ isoforms of a protein with $M_{\mathrm{r}}$ of approximately 20000 (Fig. 1).

\section{Experiment 2}

Nondialysable radioactivity per gram of uterine tissue cultured decreased linearly $(P<0.01)$ with increase in age (Fig. 2). 

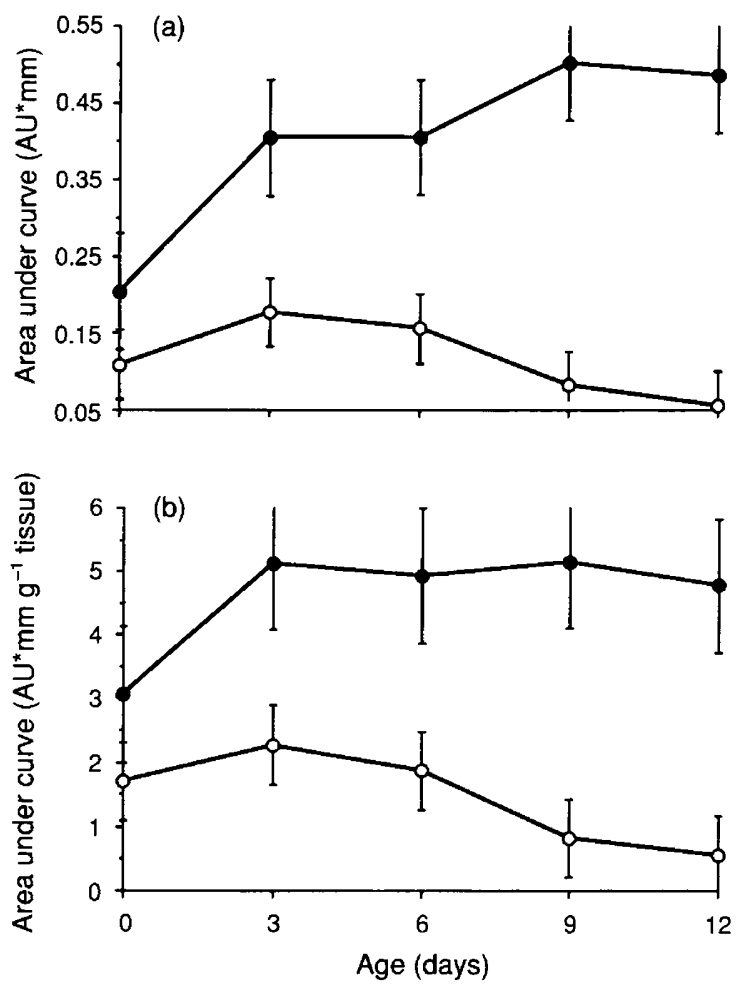

Fig. 4. Means for densitometric measurements (area under the curve) for both the 20000 and $19000 M_{\mathrm{r}}$ bands from immunoprecipitation analysis of uterine proteins from neonate gilts using anti-human retinol-binding protein (RBP) antiserum (see Fig. 3). (a) Area under the curve and (b) area under the curve corrected for cultured tissue mass are illustrated. Secretion of $(\bullet)$ the $20000 M_{\mathrm{r}}$ protein immunoreactive (RBP) increased $(P<0.01$ before and $P=0.07$ after correction for tissue mass) from day 0 to day 3 and then did not change during days 3-12. Secretion of $(c)$ the $19000 M_{\mathrm{r}}$ protein (possible immunoreactive RBP) did not change from days $0-6$, decreased $(P<0.05$ before and after correction for tissue cultured) from day 6 to day 9 and remained low on day 12 .

Visual inspection of the fluorographs indicated that uterine secretion of immunoreactive RBP increased as early as day 3 , and that uteri of 0 -, 3- and 6-day-old gilts secreted two $M_{\mathrm{r}}$ variants of immunoreactive RBP with approximate $M_{\mathrm{r}}$ of 20000 and 19000 (Fig. 3). Secretion of the lower $M_{\mathrm{r}}$ variant decreased on days 9 and 12 . These results were confirmed by densitometry (Fig. 4). Orthogonal contrasts comparing the secretion of the $20000 M_{\mathrm{r}}$ immunoreactive RBP variant indicated that secretion of this variant increased $(P<0.01$ before and $P=0.07$ after correction for tissue mass in culture) from day 0 to day 3 but did not differ from days 3-12. Secretion of the $19000 M_{\mathrm{r}}$ variant did not differ from day 0 to day 6 , significantly decreased $(P<0.05$ before and after correction for tissue mass cultured) from day 6 to day 9 and remained low on day 12 .

\section{Experiment 3}

Plasma RBP increased (main effect of treatment, $P=0.06$ ) in retinyl palmitate-treated gilts (least squares means \pm SEM was $49.5 \pm 3.6 \mu \mathrm{g} \mathrm{ml}^{-1}$ ) compared with controls (38.6 \pm $\left.4.0 \mu \mathrm{g} \mathrm{ml}^{-1}\right)$ as did plasma retinol $(5430 \pm 208$ compared with $256 \pm 232 \mathrm{ng} \mathrm{ml}^{-1}$, respectively; $P<0.01$ ). Plasma progesterone increased (main effect of treatment, $P<0.01$ ) in progesterone-treated gilts $\left(12.1 \pm 0.50 \mathrm{ng} \mathrm{ml}^{-1}\right)$ compared with controls $\left(0.18 \pm 0.50 \mathrm{ng} \mathrm{ml}^{-1}\right)$. No effect of day, or treatment by day interaction, was detected for plasma RBP, retinol or progesterone.

Repeatability of histomorphometric measurements of total uterine cross-sectional, longitudinal myometrial, circular myometrial, endometrial, glandular epithelial and luminal epithelial areas were $0.99,0.96,0.98,0.99,0.96$ and 0.96 , respectively. Duplicate measurements are therefore more than sufficient to measure treatment effects on these uterine components.

Least squares means for body mass, uterine mass, RBP secreted in culture, incorporation of $\left[{ }^{35} \mathrm{~S}\right]$ methionine into nondialysable macromolecules and total uterine cross-sectional, longitudinal myometrial, circular myometrial, endometrial, glandular epithelial and luminal epithelial areas are summarized (Table 1). No treatment effects were detected for body mass at 14 days of age. Uterine masses of gilts treated with oestradiol or $1 \mathrm{mg}$ tamoxifen day ${ }^{-1}$ did not differ but were greater $(P<0.01)$ than masses from the other treatment groups combined. Treatment with retinyl palmitate, progesterone or $0.1 \mathrm{mg}$ tamoxifen day $^{-1}$ had no effect on uterine mass. Progesterone treatment decreased $(P<0.05)$ uterine secretion of immunoreactive RBP compared with controls. Secretion of immunoreactive RBP by gilts treated with oestradiol or $1 \mathrm{mg}$ tamoxifen day ${ }^{-1}$ did not differ but was greater $(P<0.01)$ than the other treatment groups combined. Treatment with retinyl palmitate or $0.1 \mathrm{mg}$ tamoxifen day $^{-1}$ had no effect on immunoreactive RBP secretion. None of the treatments affected uterine incorporation of $\left[{ }^{35}\right.$ S $]$ methionine into nondialysable macromolecules. Photomicrographs of representative crosssections of uteri from the different treatment groups are shown (Fig. 5).

Total uterine cross-sectional, longitudinal myometrial, circular myometrial, endometrial, glandular epithelial and luminal epithelial areas were increased $(P<0.01)$ by treatment with oestradiol and $\mathrm{I} \mathrm{mg} \mathrm{tamoxifen} \mathrm{day}{ }^{-1}$ compared with the other treatment groups combined. However, oestradiol increased total uterine cross-sectional $(P<0.05)$, longitudinal myometrial $(P<0.01)$, circular myometrial $(P<0.05)$ and endometrial $(P<0.05)$ areas significantly more than treatment with $1 \mathrm{mg}$ tamoxifen day ${ }^{-1}$. The effects of oestradiol and tamoxifen ( $1 \mathrm{mg} \mathrm{day}^{-1}$ ) did not differ for glandular and luminal epithelial area. Tamoxifen $\left(0.1 \mathrm{mg} \mathrm{day}^{-1} ; P<0.05\right)$ and retinyl palmitate $(P<0.05)$ increased glandular epithelial area but had no effect on other uterine components. Progesterone treatment had no effect on any uterine component measured.

Simple correlations between body mass at 14 days of age, uterine mass, uterine secretion of immunoreactive RBP, incorporation of $\left[{ }^{35} \mathrm{~S}\right]$ methionine into nondialysable macromolecules, and total uterine cross-sectional, longitudinal myometrial, circular myometrial, endometrial, glandular epithelial and luminal epithelial areas are summarized (Table 2). Body mass ( $r$ ranging from 0.36 to 0.53 ) and uterine mass ( $r$ ranging from 0.66 to 0.80 ) were moderately correlated with the uterine components. Uterine immunoreactive RBP was also correlated with the uterine components $(r$ ranging from 0.38 to 0.68 ); the highest correlation was with glandular epithelial 


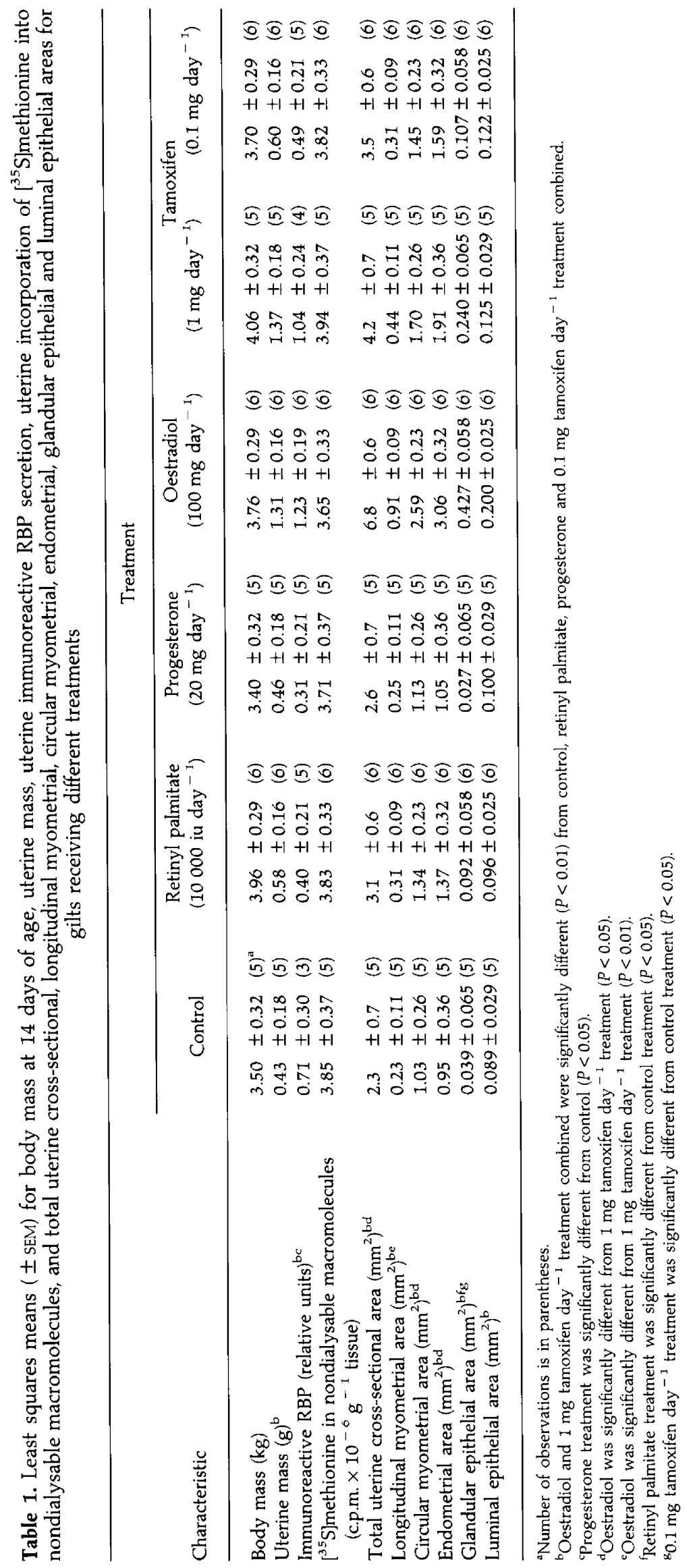



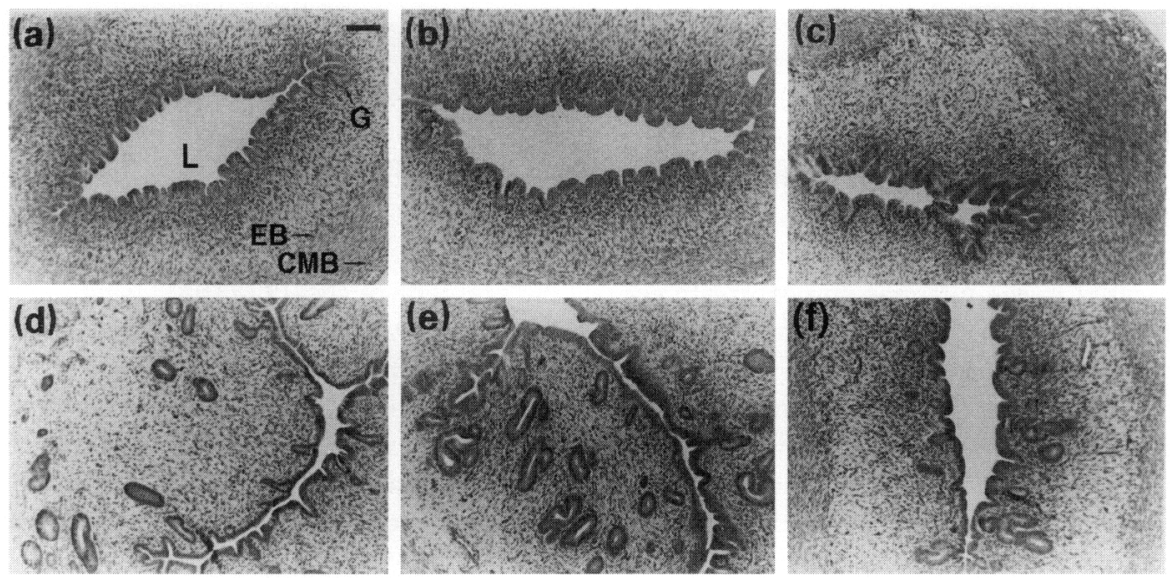

Fig. 5. Photomicrographs of representative cross-sections of uteri from neonatal gilts treated with (a) corn oil, (b) retinyl palmitate (10000 iu day ${ }^{-1}$ ), (c) progesterone (20 $\mathrm{mg} \mathrm{day}^{-1}$ ), (d) oestradiol $\left(100 \mu \mathrm{g} \mathrm{day}^{-1}\right.$ ), tamoxifen (e) $1 \mathrm{mg}$ day $^{-1}$, (f) $0.1 \mathrm{mg}$ day ${ }^{-1}$. The uterine lumen (L), an endometrial gland (G) and the endometrial (EB) and circular myometrial borders (CMB) are indicated in (a). Quantitation of areas of each component in cross-sections of the uterus are summarized in Table 1 . Scale bar represents $100 \mu \mathrm{m}$.

Table 2. Simple correlations between body mass at 14 days of age (BMT), uterine mass (UMT) uterine immunoreactive retinol-binding protein secretion (irRBP), uterine incorporation of $\left[{ }^{35} \mathrm{~S}\right]$ methionine into nondialysable macromolecules (UINDM), and total uterine cross-sectional (TUCA), longitudinal myometrial (LMA), circular myometrial (CMA), endometrial (EA), glandular epithelial (GEA) and luminal epithelial (LEA) areas for gilts in Experiment 3

\begin{tabular}{lccccccccc}
\hline & UMT & irRBP & UINDM & TUCA & LMA & CMA & EA & GEA & LEA \\
\hline BMT & \multirow{2}{*}{$0.53^{\mathrm{c}}$} & 0.02 & 0.09 & $0.40^{\mathrm{b}}$ & $0.42^{\mathrm{b}}$ & $0.36^{\mathrm{b}}$ & $0.40^{\mathrm{b}}$ & $0.37^{\mathrm{b}}$ & $0.53^{\mathrm{c}}$ \\
UMT & & $0.53^{\mathrm{c}}$ & -0.03 & $0.74^{\mathrm{c}}$ & $0.67^{\mathrm{c}}$ & $0.66^{\mathrm{c}}$ & $0.78^{\mathrm{c}}$ & $0.80^{\mathrm{c}}$ & $0.73^{\mathrm{c}}$ \\
irRBP & & & 0.22 & $0.56^{\mathrm{c}}$ & $0.47^{\mathrm{c}}$ & $0.51^{\mathrm{c}}$ & $0.60^{\mathrm{c}}$ & $0.68^{\mathrm{c}}$ & $0.38^{\mathrm{b}}$ \\
UINDM & & & & -0.02 & -0.01 & -0.07 & 0 & -0.04 & 0.08 \\
TUCA & & & & & $0.93^{\mathrm{c}}$ & $0.97^{\mathrm{c}}$ & $0.98^{\mathrm{c}}$ & $0.92^{\mathrm{c}}$ & $0.88^{\mathrm{c}}$ \\
LMA & & & & & $0.89^{\mathrm{c}}$ & $0.86^{\mathrm{c}}$ & $0.85^{\mathrm{c}}$ & $0.86^{\mathrm{c}}$ \\
CMA & & & & & & $0.92^{\mathrm{c}}$ & $0.83^{\mathrm{c}}$ & $0.81^{\mathrm{c}}$ \\
EA & & & & & & & & $0.94^{\mathrm{c}}$ & $0.86^{\mathrm{c}}$ \\
GEA & & & & & & & & & \\
\end{tabular}

${ }^{a}$ Number of observations for each correlation was 28 for correlations with irRBP and 33 for all others.

${ }^{\mathrm{b} C}$ Correlation is significant $(P<0.05)$.

'Correlation is significant $(P<0.01)$.

area. Uterine components were all highly correlated with each other ( $r$ ranging from 0.75 to 0.98 ). Uterine incorporation of $\left.{ }^{35} \mathrm{~S}\right]$ methionine into nondialysable macromolecules was not correlated with any other trait measured.

\section{Discussion}

Results of the work presented here indicate that a protein that crossreacts with anti-human RBP antiserum is synthesized and secreted by the uteri of neonatal gilts; secretion of immunoreactive RBP increases coincident with initiation of uterine gland development; treatment with retinyl palmitate increases endometrial gland epithelial area without influencing other uterine components; and oestradiol and tamoxifen treatments stimulate endometrial gland development and uterine immunoreactive RBP secretion. In contrast to the effect of progesterone on endometrial RBP secretion in mature gilts (Adams et al., 1981), secretion of immunoreactive RBP by uterine tissues of neonatal gilts was inhibited by progesterone treatment. The $20000 M_{\mathrm{r}}$ form of immunoreactive RBP identified here has the same $M_{\mathrm{r}}$ and similar $\mathrm{pI}$ as serum and uterine RBP from mature gilts (Rask, 1974; Clawitter et al., 1990; Harney et al., 1990). Together, these results suggest that the protein is RBP, and that RBP and retinol play a role in the development of uterine glands in neonates. However, owing to contamination of the cultures with RBP from serum, it was not possible using amino-terminal sequencing or retinol-binding studies to ascertain whether this protein was RBP.

The increase in immunoreactive RBP secretion that occurs coincident with the initiation of uterine gland development 
suggests that increased immunoreactive RBP secretion either participates in, or results from, gland development. However, it is possible that the coincident increase is unrelated to the process of gland development. Neonatal gilts were treated with retinyl palmitate to observe its effect on gland epithelial area in uterine cross-sections. Although the dosage given was higher than physiological concentrations, it is difficult to assess whether the dosage resulted in the pharmacological treatment of gilts with retinol, because the rate of conversion of retinyl palmitate to retinol by uterine tissues and their ability to take up retinol in this form are not known. Furthermore, tissues (such as the liver) may metabolize retinyl palmitate to retinol and secrete the retinol bound to RBP which would then be available to other tissues. Results indicated that while retinol in the plasma (a measure of retinyl palmitate and other retinoids) was high, RBP was increased by $28 \%$, which is a physiological increase. However, the observation that treatment with retinyl palmitate specifically stimulated gland epithelial area suggests that retinol participates in the process of gland development. Although it was not possible to distinguish between hyperplastic and hypertrophic growth in this experiment, either type of growth may be involved in normal uterine gland development. As RBP is the normal carrier of retinol, immunoreactive RBP may participate in gland development. Although retinyl palmitate did not stimulate uterine secretion of immunoreactive RBP, it did stimulate plasma RBP concentrations. It seems plausible that uterine secretion of immunoreactive $R B P$ is influenced by plasma RBP or retinol concentrations. Thus exogenous retinol could stimulate gland development without coincident increased stimulation of uterine immunoreactive RBP.

The effect of progesterone treatment on total protein and uterine secretion of immunoreactive RBP differs in neonatal gilts from that in mature gilts. Concentrations of progesterone in the plasma of the progesterone-treated neonatal gilts were similar to those that occur during pregnancy (Robertson and King, 1974) and the dosage used was similar to that used to induce secretion of endometrial protein (Knight et al., 1974) and RBP (Adams et al., 1981) in mature gilts. Decreased secretion of immunoreactive RBP suggests that the neonatal uterus has functional progesterone receptors. Differences in progesterone receptor concentrations, distribution or function might explain the difference observed in neonatal and mature uterine tissues.

Treatment of neonatal ewes with the synthetic progestin norgestomet inhibited uterine gland development (Bartol et al., 1988). Treatment of neonatal mice with $40 \mathrm{mg}$ progesterone $\mathrm{kg}^{-1}$ inhibited uterine epithelial $\left[{ }^{3} \mathrm{H}\right]$ thymidine uptake and the mitotic index (Bigsby and Cunha, 1985). These findings suggest that the withdrawal of maternal progesterone that occurs at birth influences uterine gland development. However, the results reported here do not support this contention for gilts.

Results from this study indicate that tamoxifen acts as an oestrogen agonist in pigs (as previously reported by Lin and Buttle, 1991), and that tamoxifen stimulated uterine gland development while having little influence on other components of the uterus. These results are in contrast to those found in rats by Branham et al. (1985a). Thus, the response of different species to oestrogen agonist or antagonist compounds differ and care is required when predicting the response to a particular oestrogenic or anti-oestrogenic compound.
Two $M_{r}$ forms of immunoreactive RBP were immunoprecipitated from medium in which neonatal uterine tissues were cultured. However, the identification of the $19000 \mathrm{M}_{\mathrm{r}}$ band as RBP is inconclusive because many bands, in addition to immunoreactive RBP, appear to be specifically immunoprecipitated. There appears to be only a single gene for RBP in pigs (Stallings-Mann et al., 1993). Thus, a possible explanation for the presence of the $19000 M_{\mathrm{r}}$ band is proteolytic cleavage of the $20000 M_{\mathrm{r}}$ form; proteolytic cleavage of RBP could release retinol to target tissues. Alternatively, the $19000 M_{\mathrm{r}}$ protein could be nonspecifically bound by the antiserum. Regardless of the correct explanation, the observation that the amount of this protein changes coincident with initiation of uterine gland development makes it of interest and the origin of this band should be investigated.

Uterine mass and the areas of all components of uterine structure correlated with body mass, suggesting that, during the period examined, nutrition of neonatal gilts influences uterine growth and development. Nutrition in piglets depends on milk supply, which is influenced by maternal milk production and competition among littermates. The influence of differences in neonatal nutrition on later uterine function requires further investigation.

In conclusion, this study demonstrates that a protein with immunochemical crossreactivity with RBP (immunoreactive RBP) is secreted by porcine uteri in association with the initiation of uterine gland development. Treatment with oestradiol and $1 \mathrm{mg}$ tamoxifen day ${ }^{-1}$ stimulated both uterine gland development and immunoreactive RBP secretion. Gland epithelial area had the highest correlation with uterine immunoreactive RBP secretion of the uterine wall components. Retinyl palmitate treatment stimulated uterine gland epithelial area without affecting other uterine components. These results suggest an association between uterine gland development and uterine RBP secretion. Further studies are necessary to elucidate the role of retinol and RBP in neonatal uterine gland development.

Names are necessary to report factually on available data; however, the USDA neither guarantees nor warrants the standard of the product, and the use of the same by USDA implies no approval of the product to the exclusion of others that may also be suitable. F. F. Bartol was supported in part by USDA-NRICGP Grant No. 91-37203-6605.

\section{References}

Adams KL, Bazer FW and Roberts RM (1981) Progesterone-induced secretion of a retino-binding protein in the pig uterus Journal of Reproduction and Fertility $62 \quad 39-47$

Bal HS and Getty R (1970) Postnatal growth of the swine uterus from birth to six months Growth 34 15-30

Bartol FF, Wiley AA, Coleman DA, Wolfe DF and Riddell MG (1988) Ovine uterine morphogenesis: effects of age and progestin administration and withdrawal on neonatal endometrial development and DNA synthesis Journal of Animal Science 66 3000-3009

Bigsby RM and Cunha GR (1985) Effects of progestins and glycocorticoids on deoxyribonucleic acid synthesis in the uterus of the neonatal mouse Endocrinology 117 2520-2526

Branham WS, Sheehan DM, Zehr DR, Medlock KL, Nelson CJ and Ridlon E (1985a) Inhibition of rat uterine gland genesis by tamoxifen Endocrinology $1172238-2248$ 
Branham WS, Sheehan DM, Zehr DR, Ridlon E and Nelson CJ (1985b) The postnatal ontogeny of rat uterine glands and age related effects of 17ß-estradiol Endocrinology 117 2229-2237

Cancela ML and Price PA (1992) Retinoic acid induces matrix Gla protein gene expression in human cells Endocrinology 130 102-108

Christenson RK, Bartol FF, Vallet JL, Wiley AA and Spencer FE (1992) Comparative study of uterine morphogenesis and protein secretion in neonatal Meishan (MS) and White crossbred (xb) pigs Journal of Animal Science 70 (Supplement 1) 264 (Abstract)

Christenson RK, Leymaster KA and Young LD (1987) Justification of unilateral hysterectomy-ovariectomy as a model to evaluate uterine capacity in swine Journal of Animal Science 65 738-744

Clawitter J, Trout WE, Burke MG, Araghi S and Roberts RM (1990) A novel family of progesterone-induced, retinol-binding proteins from uterine secretions of the pig Journal of Biological Chemistry 265 3248-3255

DeLuca LM (1991) Retinoids and their receptors in differentiation, embryogenesis and neoplasia FASEB Journal 5 2924-2933

Goodman DS (1979) Vitamin A and retinoids: recent advances: introduction, background and general overview Federal Proceedings 38 2501-2503

Hadek R and Getty R (1959) The changing morphology in the uterus of the growing pig American journal of Veterinary Research 20 573-577

Harney JP, Mirando MA, Smith LC and Bazer FW (1990) Retinol-binding protein: a major secretory product of the pig conceptus Biology of Reproduction $\mathbf{4 2}$ 523-532

Knight JW, Bazer FW, Wallace HD and Wilcox CJ (1974) Dose-response relationships between exogenous progesterone and estradiol and porcine uterine protein secretions Journal of Animal Science 39 747-751

Lin Cl and Buttle HL (1991) Effect of oestradiol benzoate and tamoxifen on the growth of and induction of progesterone receptors in the uterus and mammary gland of immature pigs Journal of Endocrinology 130 259-265

National Research Council (1988) Nutrient Requirements of Swine, Ninth Edn pp 51. National Academy Press, Washington DC

Rask L (1974) The vitamin A transporting system in porcine plasma European Journal of Biochemistry 44 I-5

Rickles RJ, Darrow AL and Strickland S (1989) Differentiation-responsive elements in the 5 ' region of the mouse tissue plasminogen activator gene confer two-stage regulation by retinoic acid and cyclic AMP in teratocarcinoma cells Molecular and Cellular Biology 9 1691-1704

Roberts RM, Baumbach GA, Buhi WC, Denny JB, Fitzgerald LA, Babelyn SF and Horst MN (1984) Analysis of membrane polypeptides by two-dimensional polyacrylamide gel electrophoresis. In Molecular and Chemical Characterization of Membrane Receptors Vol. 3 pp 61-113 Eds JC Venter, LC Harrison. Alan R. Liss, Inc., New York
Robertson HA and King GJ (1974) Plasma concentrations of progesterone, oestrone sulphate in the pig at implantation, during pregnancy and at parturition journal of Reproduction and Fertility 40 133-14I

Ronne H, Ocklind C, Wiman K, Rash L, Obrink B and Peterson PA (1983) Ligand-dependent regulation of intracellular protein transport: effect of vitamin $A$ on the secretion of the retinol-binding protein Journal of Cell Biology 96 907-910

Selvaraj RJ and Sushella TP (1970) Estimation of serum vitamin A by a microfluorometric procedure Clinica Chimica Acta 27 165-170

Spencer TE, Wiley AA and Bartol FF (1992) Neonatal age and period of estrogen exposure affect porcine uterine growth, morphogenesis and protein synthesis Biology of Reproduction $\mathbf{4 8} 741-751$

Stellmach V, Leask A and Fuchs E (1991) Retinoid-mediated transcriptional regulation of keratin genes in human epidermal and squamous cell carcinoma cells Proceedings National Academy of Sciences USA 88 4582-4586

Stallings-Mann ML, Trout WE and Roberts RM (1993) Porcine uterine retinolbinding proteins are identical gene products to the serum retinol-binding protein Biology of Reproduction 48 998-1005

Trout WE, McDonnell JJ, Kramer KK, Baumbach GA and Roberts RM (1991) The retinol-binding protein of the expanding pig blastocyst: molecular cloning and expression in trophectoderm and embryonic disc Molecular Endocrinology 5 1533-1540

Trout WE, Hall JA, Stallings-Mann ML, Galvin JM, Anthony RV and Roberts RM (1992) Steroid regulation of the synthesis and secretion of retinol-binding protein by the uterus of the pig Endocrinology 130 2557-2564

Vallet JL (1993) Purification and properties of porcine allantoic fluid retinol-binding protein Biology of Reproduction 48 (Supplement 1) 140 (Abstract)

Vallet JL (1994) Technical note: a radioimmunoassay for porcine retinol binding protein Journal of Animal Science 72 2449-2454

Vallet JL and Christenson RK (1993) Uterine space affects placental protein secretion in swine Biology of Reproduction 48 575-584

Vasios GW, Gold JD, Petkovich M, Chambon P and Gudas LJ (1989) A retinoic acid-responsive element is present in the $5^{\prime}$ flanking region of the laminin BI gene Proceedings of the National Academy of Sciences USA 86 9099-9103

Yuspa SH, Ben T and Steinert P (1982) Retinoic acid induces transglutaminase activity but inhibits cornification of cultured epidermal cells Journal of Biological Chemistry $2579906-9908$ 